\title{
Laboratory study of odour emissions from areal sources: evaluation of a sampling system
}

\author{
C. Leyris ${ }^{1,2}$, F. Maupetit ${ }^{2}$, J.-M. Guillot ${ }^{1 *}$, L. Pourtier ${ }^{2}$, J.-L. Fanlo ${ }^{1}$ \\ ${ }^{1}$ Laboratoire Génie de l'Environnement Industriel, École des Mines d'Alès, 6, avenue de Clavières, 30319 Alès Cedex, France \\ ${ }^{2}$ E.O.G., 70, rue Pierre Duhem, Z.I. des Milles, 13856 Aix en Provence Cedex 3, France
}

Odour emissions from various sources are of increasing concern to the public. Considering areal sources, there is need for the development of reliable methods for the measurement of odour emissions because none is yet accepted as a standard.

In this work, a wind tunnel was first developed as a tool to measure odour emission from areal sources. A laboratory study on concentrations above the liquid surface was carried out to characterise the emission. Edge and fetch influence was shown as well as the presence of concentration gradients.

Then, a dynamic flux chamber was developed as a sampling emission rate system. Tests in the wind tunnel showed good accuracy and precision.

\section{Introduction}

Odour has become one of the most serious environmental concerns around the world during the past twenty years. The determination of odour source strength is the first step in solving an odour problem. In order to classify and compare odour sources in industrial plants, the odour emission rates must be known. Then, these data can be fitted into a dispersion model to calculate the odour concentration in the vicinity of a plant. Such a calculation may reflect complaints from residents and also help the operating authority to determine an appropriate strategy for odour control in both existing and new plants. Emissions can be divided into two general classes: canalised emissions (factory chimneys) and diffuse emissions (evaporation ponds, oxidation lagoons). As odour emission is defined commonly as being the product of the rejected air flow rate (D) by the odour concentration (OC), measuring emissions from canalised sources appears easy. On the contrary, odour concentration above a liquid surface open to the atmosphere is not as homogeneous as in a chimney and in the case of an areal source, there is no rejected air flow rate. Therefore, among these general classes of odour sources, determining odour emissions from areal sources is the most difficult task because it needs the measurement of both odour concentration and flow rate.

For the determination of odour concentration, some authors [1,2] propose to collect odour samples by purging the liquid sample by odourless air. The odour level of the stripped air is determinated by olfactometry. This method forces the mass transfer and is not therefore representative of mass transfer in field. Others authors $[3,4]$ use an Odour and Emission Chamber (OEC) in which up to 200 liters of 
liquid can be exposed to an enclosed atmosphere under a controlled wind. The determination of odour concentration is realised from headspace samples in the OEC. This method interferes with the process of volatilization because of pollutant accumulation in the enclosed atmosphere.

The most current method is the use of an enclosure device (flux chamber) to sample gaseous emissions from a defined surface area of the source. Clean air is added to the chamber at a fixed controlled rate and is released through the chamber's exit. Emitted odour and odorous compounds concentration are measured in the exit gas. These direct sampling systems are divided into two groups: static [5-9] and dynamic systems [10-12].

Static methods require the gas to be supplied at a flow rate from 5 to $24 \mathrm{~L} \cdot \mathrm{min}^{-1}$. The mixing characteristics of the chemicals and the carrier gas are the critical design parameters. Mass transfer by molecular diffusion takes place above the confined surface. However, several uncertainties have been reported. The selection of the sweep air rate is not fully satisfactory. It was found that increasing the sweep air rate did not alter the chemical concentration inside the isolation chamber. Furthermore, measured emission rates largely depend on the configuration of the enclosure and operating procedures [13]. Moreover, the use of the isolation chamber leads to an underestimation of the emission rate [14].

Dynamic methods require carrier gas to be supplied at a much higher flow rate, generally to produce air velocities of 0.3 to $1.0 \mathrm{~m} \cdot \mathrm{s}^{-1}$. The aerodynamic performance of the enclosure is the critical design parameter. This system is intended to create an environment where the boundary layer is well developed. Convective mass transfer takes place above the confined surface.

As we previously explained, odour emission determination supposes an evaluation of rejected air flow rate. Because of the lack of real rejected air, different methods for evaluating a flow rate are proposed. First, the flow rate used for the odour emission calculation is often the air flow rate applied in the flux chamber. However, some authors $[15,16]$ propose to multiply the source area of the source by the prevailing wind speed.

Dealing with the determination difficulty of odour concentration and air rejected flow rate, global methods were also studied: Kinetics in an OEC [17] or back calculation with the use of gaussian dispersion model $[18,19]$. But estimating the area emission based on dispersion models requires the estimation of atmospheric parameters as well as evaluation of the surrounding terrain and its effect on the dispersion. There are inadequate methods of accounting for other than ideal flat terrain, and methods based on dispersion also require relatively small changes in wind velocity and direction over an extended time. To resume, because of uncertainty associated with each technique, none of them is yet accepted as a standard method.

In France, regulation advises to canalise odorous emissions from an areal source but the NF X 43-104 norm only proposes a relative method (dynamic flux chamber) which allows to compare sources. The accuracy of this dynamic flux chamber have not been yet evaluated. Therefore, our work aims to develop a flux chamber based on the norm model and to evaluate the accuracy of the method. In this intention, the first step was the development of a wind tunnel, which simulates the wind action on a liquid surface in field. The second step was the development of a dynamic flux chamber.

Thus, this paper is divided into two parts: firstly, it presents a laboratory study of pollutant concentrations near the source, above the liquid surface. Air samples are collected in different locations according to the height, width and length of the tank. Pollutant concentrations and odour level are measured. The second part is devoted to the precision and accuracy of the performed dynamic flux chamber system. These studies are devoted to liquid sources and only one odorous compound, the diethyl sulphide, is present in water solution.

\section{Materials and methods}

The chosen odorous pollutant was diethyl sulphide (Acros, $98 \%)$ because of its low odour threshold $\left(0.014 \mathrm{mg} \cdot \mathrm{m}^{-3}\right.$ [20]).

\section{Wind tunnel}

The study is conducted in a wind-wave tank, schematically shown in figure 1 . The tank in stainless steel is $125 \mathrm{~cm}$ long, $20 \mathrm{~cm}$ deep and $60 \mathrm{~cm}$ wide under a $9 \mathrm{~m}$ long wind tunnel, $1 \mathrm{~m}$ wide and $50 \mathrm{~cm}$ high in cross section constructed such that the air flow joins the water surface tangentially. A blade fan connected to a frequency variator (Leroy Somer FMV 2107) generates air flows corresponding to wind speeds from 0.5 to $4.5 \mathrm{~m} . \mathrm{s}^{-1}$. The part A of the tunnel is devoted to ensure a uniform velocity distribution. The part B contains the tank filled with a water solution of the model pollutant. The diethyl sulphide concentrations in air are measured above the tank (see figure 2) at different heights: 2, 12, 22, 32 and $42 \mathrm{~cm}$ from the interface air-water. The part $\mathrm{C}$ is the tunnel outlet where the pollutant concentration is sure to be homogenous as a result of blade fan action.

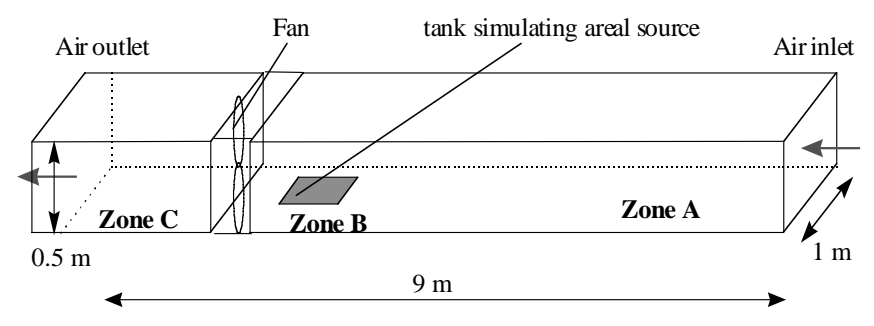

Figure 1. Scheme of the wind tunnel. 


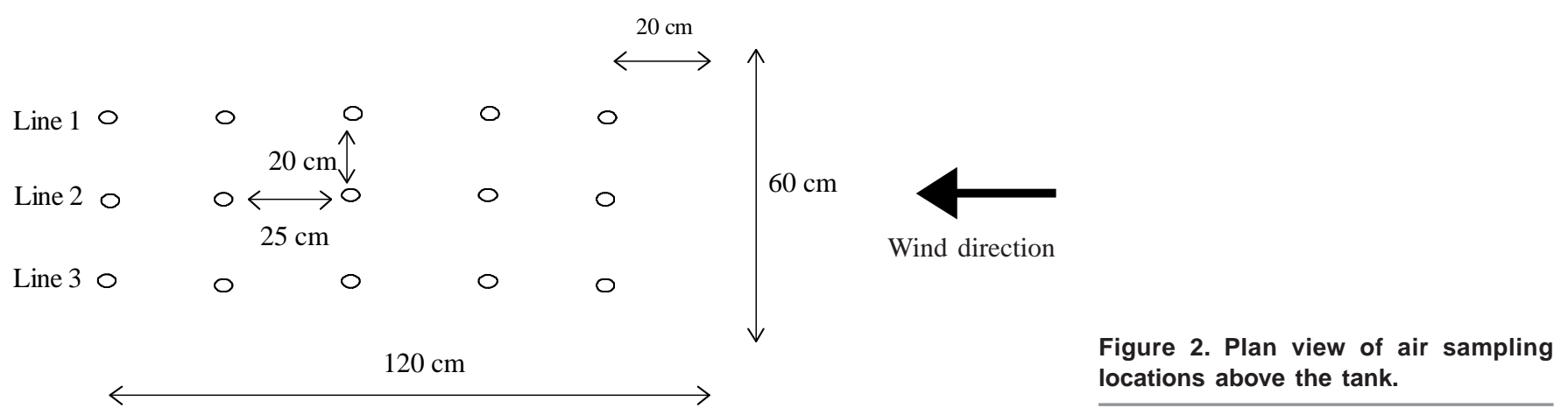

\section{Dynamic flux chamber}

The flux chamber is constructed in perspex (Plexiglass) and is $120 \mathrm{~cm}$ long, $15 \mathrm{~cm}$ deep and $18 \mathrm{~cm}$ high. It consists of several parts: its inlet with a honeycomb is devoted to ensure a uniform velocity distribution. In the main section, the base of the flux chamber is opened to the liquid source and encloses $0.156 \mathrm{~m}^{2}$ of liquid surface. The outlet of the flux chamber is connected to a blade fan, which can generate air flows corresponding to wind speeds from 0.5 to $5 \mathrm{~m} . \mathrm{s}^{-1}$. The chamber is placed on the liquid surface so that the air flow inlet is in front of the odorous source. By this way, the inlet air flow is sure to be odourless.

\section{Analytical methods}

For experiment 2, concentrations of total hydrocarbons were monitored in the tunnel using portable flame ionization detector (FID) (COSMA, Graphite 730). The furnace temperature was maintained at $225{ }^{\circ} \mathrm{C}$ and the sampling flow rate was fixed to $50 \mathrm{~L} \cdot \mathrm{h}^{-1}$. Gas pressure values were $400 \mathrm{hPa}$ for air and $700 \mathrm{hPa}$ for hydrogen.

For all the other experiments, diethyl sulphide concentrations in air were determined by gas chromatography associated to a flame ionization detector (GC/FID). A Hewlett Packard model HP-5890 series II chromatograph with gas valve was configured as follows: a $30 \mathrm{~m}$ apolar methyl siloxane column (HP-1) with an internal diameter of $0.53 \mathrm{~mm}$ and a $2.65 \mu \mathrm{m}$ film thickness was used. The flow rate of helium (the carrier gas) was $14 \mathrm{~mL} \cdot \mathrm{min}^{-1}$. The GC conditions were $130{ }^{\circ} \mathrm{C}$ (isotherm) for the furnace and $150{ }^{\circ} \mathrm{C}$ for the injector. The end of the column was directly link to the flame ionization detector (FID) whose temperature was kept at $200{ }^{\circ} \mathrm{C}$. Gas flows rates were: $\mathrm{H}_{2}$, $40 \mathrm{~mL} \cdot \mathrm{min}^{-1}$ and checked air, $290 \mathrm{~mL} \cdot \mathrm{min}^{-1}$.

Olfactometric analyses were carried out with a dynamic olfactometer (Proviron) which satisfies the recommendations of the NF X 43-101 norm. Such an olfactometer has three sniffing ports and is of forced choice type. Air was presented to the panellist through two ports for odourless air and through the other for diluted odorous air. Tests were carried out on four panellists.

\section{Methodology}

\section{Wind tunnel study}

Diethyl sulphide concentration in water was 1 g.L $\mathrm{L}^{-1}$. The wind speed was $1 \mathrm{~m} . \mathrm{s}^{-1}$ for experiment 1 and successively increased from 1,3 to $5 \mathrm{~m} . \mathrm{s}^{-1}$ for experiment 2 . Vertical sampling locations were defined by the mean of stainless steel tubings ( 0.75 inch in diameter) with different lengths. These tubings were connected with pumps which fill Tedlar bags in experiment 1 and with portable flame ionization detector in experiment 2. Horizontal sampling locations are represented by elliptic forms in figure 2 .

\section{Flux chamber accuracy and precision}

Emission rate from covered surface is calculated by averaging two emission rates of each twenty minutes. The test is performed in a short time (40 minutes) so there is no significant decrease in diethyl sulphide concentration in water. Gaseous samples are collected behind the fan. Average velocity is measured with hot wire anemometer (VTM, KIMO) in the main section to calculate the flow rate through the flux chamber.

The precision and accuracy are determined under the following conditions: diethyl sulphide concentration in liquid ranges from $100 \mathrm{mg} . \mathrm{L}^{-1}$ to $1 \mathrm{~g} . \mathrm{L}^{-1}$ and wind speed varies from 1 to $5 \mathrm{~m} \cdot \mathrm{s}^{-1}$.

Accuracy of the method is estimated by comparing the emission of the tank surface isolated by the flux chamber with the emission of the tank without flux chamber for the same operating conditions. Accuracy is expressed as percent bias by using the equation (1):

$$
\% \text { bias }=\frac{\mathrm{E}_{\mathrm{CF}}-\mathrm{E}_{\mathrm{T}}}{\mathrm{E}_{\mathrm{T}}} \times 100
$$

where $E_{C F}$ is the emission measured in the chamber and $E_{T}$ is the emission measured in the wind tunnel without the flux chamber.

The precision is estimated by calculating the relative standard deviation for sets of duplicate measurements. The 
influence of the flux chamber presence on tank emission measurements is determined by comparing tank emission measurements with and without flux chamber present (total emission compared with uncovered surface emission).

\section{Results - Discussion}

\section{Wind tunnel study}

\section{Experiment 1}

The tank was filled with a water solution of diethyl sulphide at $1 \mathrm{~g} . \mathrm{L}^{-1}$ and exposed to the wind speed of $1 \mathrm{~m} . \mathrm{s}^{-1}$. The concentration profiles in the gaseous phase are shown in figure 3. No uniformity of concentrations is found in a given section of the tunnel (and therefore uniformity of odour concentration as the study only concerns one pollutant).

On one hand, diethyl sulphide and odour concentrations decrease very strongly in the first ten centimetres. On the other hand, they are constant from $20 \mathrm{~cm}$ above the waterair interface to the top of the tunnel.

The existence of this gradient can be explained by the wind influence on the transfer phenomenon. Actually, the transfer in an isolated system is only carried out by molecular diffusion until thermodynamic equilibrium between water and air. In the case of an open system as the wind tunnel, wind action favours convective transfer and the balance between liquid and gas phases incessantly moves.

\section{Experiment 2}

Concentration profile above the tank

Diethyl sulphide concentration in water was 1 g.L. $\mathrm{L}^{-1}$ and the wind speed successively increased from 1,3 and 5 m.s. ${ }^{-1}$ in this experiment.

A typical concentration profile is shown in figure 4 for a sampling location at $2 \mathrm{~cm}$ above the liquid source. Indeed, the very low concentrations previously measured above $20 \mathrm{~cm}$ from the interface (Fig. 3) do not allow to study fetch and edge influence on concentration. This vindicates sampling location as close as possible to the interface $(2 \mathrm{~cm})$.

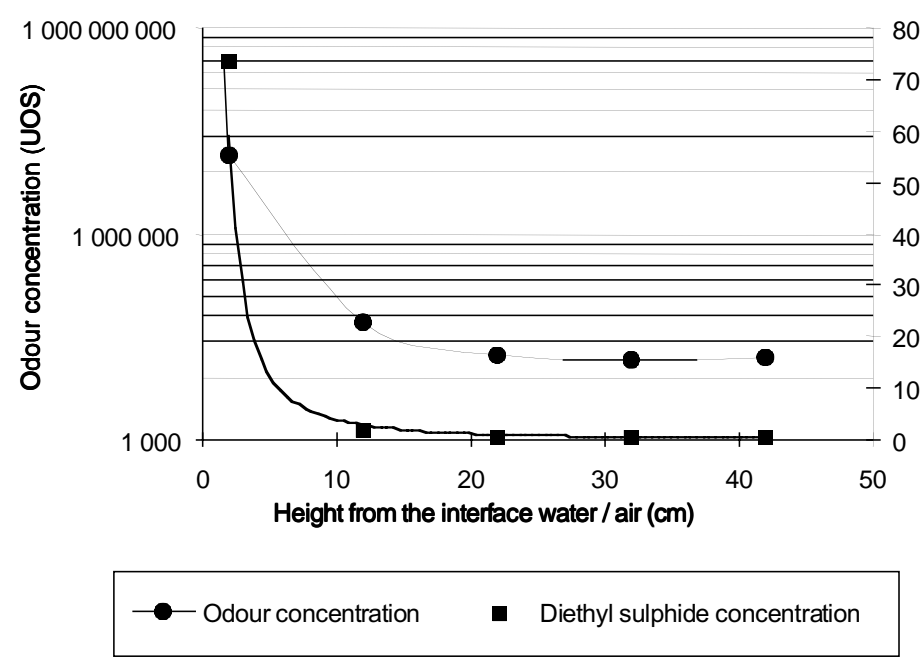

Figure 3. Odour concentration and diethyl sulphide concentration as function of distance from the waterair interface.

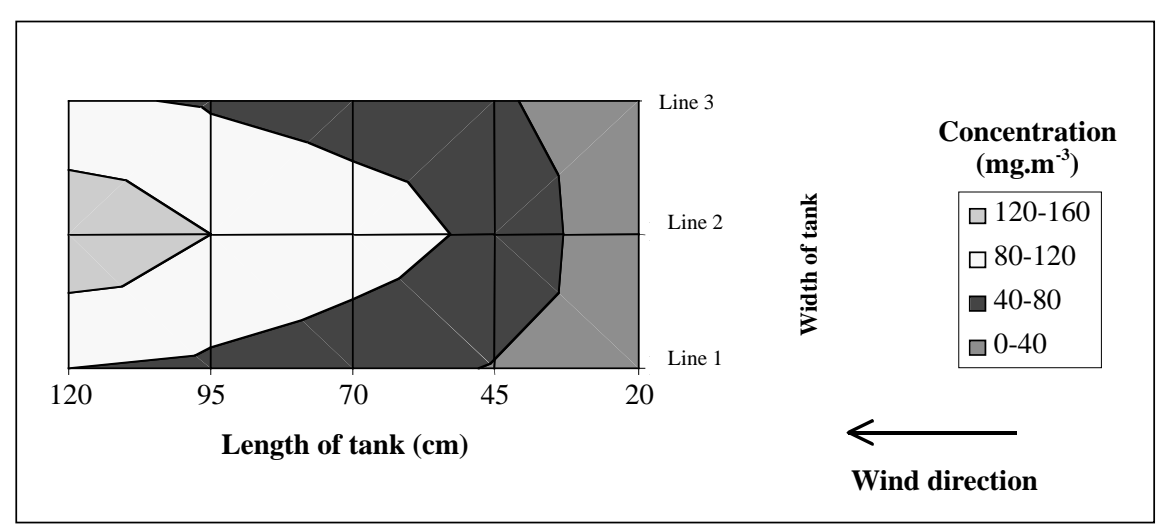

Figure 4. Typical concentration profile above the tank. 
As far as edge influence is concerned, results show that concentrations are lower following line 1 and 3 than following line 2. This edge influence cannot be correlated neither to wind speed nor to friction velocity $U^{*}$ because no significant difference is observed for these data according to lines 1,2 or 3 . As far as fetch influence is concerned, the pollutant concentration increases when fetch ranges from 20 to $110 \mathrm{~cm}$. This result is consistent with the work of Lunney [21] who modelled mass transfer coefficient $k_{1}$ depending on fetch.

Profiles for wind speed at 1 and $3 \mathrm{~m} . \mathrm{s}^{-1}$ are the same as profile presented in figure 4 . So previous conclusions about fetch and edge influence are available for the various wind speeds studied.

\section{Vertical concentration gradient}

Figure 5 represents concentration profile versus height from the interface for the line 1,2 and 3 , for maximum fetch $(1.2 \mathrm{~m})$, for diethyl sulphide concentration in water of $1 \mathrm{~g} . \mathrm{L}^{-1}$ and for a wind speed of $5 \mathrm{~m} . \mathrm{s}^{-1}$. Whatever the line and the wind speed considered, a strong concentration decrease appears in the first ten centimetres above the interface as it was observed in experiment 1. For maximum heights (up to $20 \mathrm{~cm}$ ), the concentration values are constant and low. This conclusion thus confirms the presence of concentration gradient whatever the tunnel section.

The presence of concentration gradients above the area raises the difficulty to obtain a representative sample to measure odour emitted from the source. Moreover, it involves that the traditional way to calculate odour emission (Flow $\times$ Odour concentration) cannot be applied in the tunnel. So, the difficulty in measuring odour emission in the tunnel involves finding representative parameters of odour emission. These representative parameters will be used for the determination of the sampling method accuracy.

Choice of a sampling location

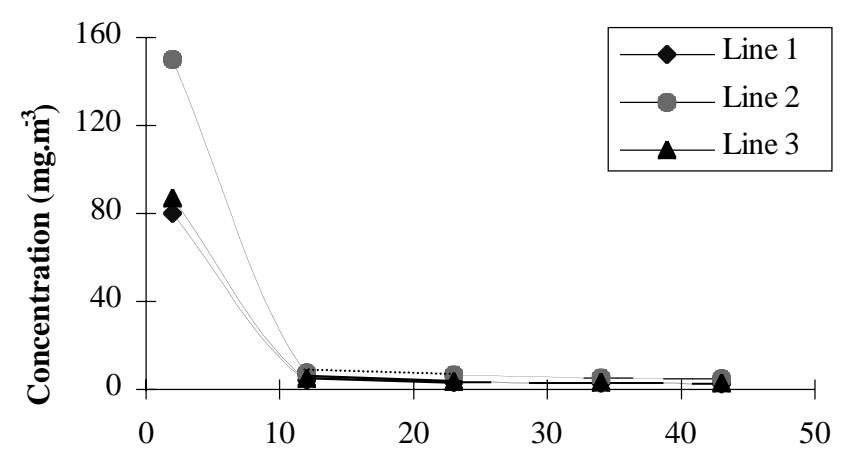

Heigths from the interface air - water (cm)

Figure 5. Diethyl sulphide concentrations as function of distance from the water-air interface.
Table I. Concentration ratio at two locations according to different operating conditions.

\begin{tabular}{ccc}
$\begin{array}{c}\text { Concentration } \\
\text { in water }\left(m g \cdot L^{-1}\right)\end{array}$ & $\begin{array}{c}\text { Wind speed } \\
\left(m \cdot s^{-1}\right)\end{array}$ & $\begin{array}{c}\text { Concentration (Point Z)/ } \\
\text { Concentration (Zone C) }\end{array}$ \\
\hline 1000 & 5 & 20.8 \\
100 & 5 & 10.5 \\
100 & 1 & 6.9 \\
\hline
\end{tabular}

A possibility studied to get over the gradient presence was to sample in the homogenous gaseous phase (in zone $\mathrm{C}$ of the tunnel). However, concentrations measured in zone $\mathrm{C}$ were diluted in comparison with those near the source in "point Z" defined by:

- Vertically: two centimetres from the interface;

- Laterally: following of the line 2;

- Longitudinally: fetch equal to $1.2 \mathrm{~m}$.

This dilution is not constant according to operating conditions (see table I). Ratio between concentrations at the two locations moves with wind speed and with pollutant concentration in water.

Considering all these informations, sampling position used to determine odour concentration was chosen where pollutant concentration is maximum not to minimise the odour emission. The previous results about gradients existing above the areal source have shown that the adequate position is the "point Z".

However, the measurement at this point cannot be used for the definition of the odour emission because of the gradients present. Then, with the impossibility to determine the odour emission in the tunnel, representative parameters of odour emission have been chosen to carry out following studies simultaneously on the pilot (wind tunnel) and sampling system (flux chamber).

\section{Representative parameters of odour emission}

Odour and odorous compound concentrations above the liquid surface indicate the odour and the quantity of odorous compounds present in air. They do not allow to measure quantity and odour emitted as a function of time. Hence, the other parameter to monitor is the mass flux of odorous component. Such a transfer is difficult to estimate in the case of an environmental source opened to the atmosphere. It is easier in the case of the tank under a wind tunnel because of the emission canalization and mass conservation principle (whereas there is not odour conservation).

To summarize, mass fluxes are representative of odorous components transfer, and odour concentration determined from gaseous sample taken in point $\mathrm{Z}$ is a significant parameter to estimate odour emitted from an areal source. So mass flux measurements are parameters that have first been chosen to evaluate the dynamic flux chamber method. 


\section{Flux chamber study}

Mass transfer depends on the wind. So aerodynamic study in the flux chamber was carried out first.

\section{Aerodynamic study}

The structure of turbulence and wind velocity profile near the interface are highly irregular and difficult to quantify, but a vertical mean logarithmic velocity (U) profile is usually assumed (equation (2)).

$$
\mathrm{U}=\frac{\mathrm{U}^{*}}{\mathrm{~K}} \ln \frac{\mathrm{z}}{\mathrm{z}_{0}}
$$

where $\mathrm{U}^{*}$ and $\mathrm{z}_{0}$ are the friction velocity and effective roughness height, respectively. $\mathrm{K}$, the Von Karman constant, is taken to be 0.4 .

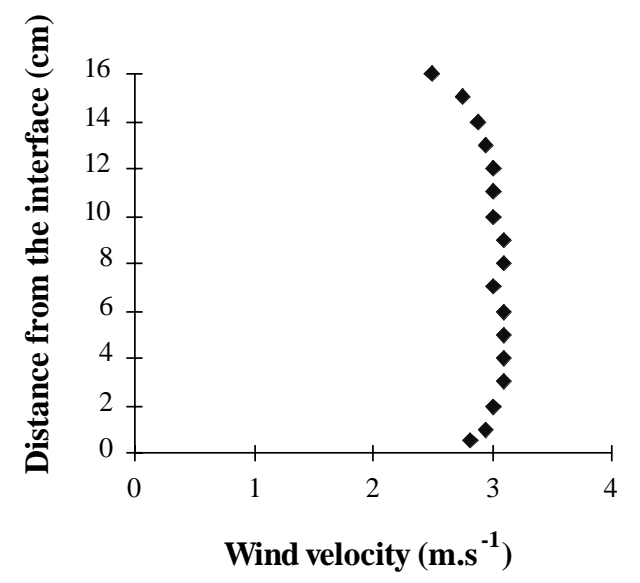

Figure 6. A typical wind speed profile in the flux chamber.
A typical turbulent velocity profile obtained in the flux chamber is represented in figure 6 . This figure shows that the air flow goes into the main section in a steady state. That ensures that every operation of the sampling system has the same flow pattern in the main section. The logarithmic velocity profile equation (2) is used to obtain the friction velocity $U^{*}$. This parameter is important for modelling mass transfer [22].

Friction velocities measurements in the flux chamber are compared with those in the wind tunnel for various wind speeds. Figure 7 shows few difference between friction velocity values in the flux chamber and in the wind tunnel for a given wind speed. But the wind tunnel values result from 15 averaged measurements made above the total liquid area whereas the flux chamber values result from one measurement made in the middle on the main section.

Despite of that, mathematical functions fitting the experimental data are quite similar:

$\begin{array}{lll}\mathrm{U}^{*}=0.0296 \mathrm{U} & \mathrm{r}^{2}=0.99 & \text { for the wind tunnel; } \\ \mathrm{U}^{*}=0.0330 \mathrm{U} & \mathrm{r}^{2}=0.94 & \text { for the flux chamber. }\end{array}$

\section{Precision and accuracy}

Duplicate chamber measurements are made under both similar conditions and different conditions in the wind tunnel. Table II lists the average emission rates found for groups of duplicate measurements, the relative standard deviation and the averaged percent bias for 9 sets of measurements grouped into 5 similar sets.

These results indicate that the method precision is good (RSD less than $10 \%$ ) according to the conditions tested. Excepted for the low emission whose values only result from one set of data, the flux chamber accuracy is as good as the precision (see averaged bias in table II).

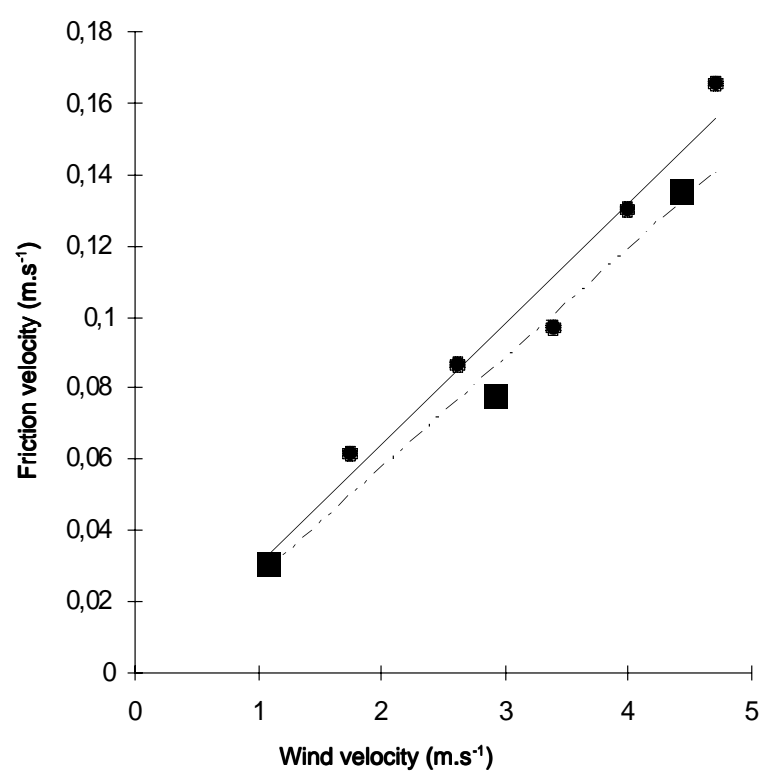

\begin{tabular}{|c|c|}
\hline$\square$ & $\begin{array}{l}\text { Friction velocity in flux } \\
\text { chamber }\end{array}$ \\
\hline 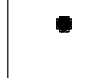 & $\begin{array}{l}\text { Friction velocity in wind } \\
\text { tunnel }\end{array}$ \\
\hline & $\begin{array}{l}\text { Linear (friction velocity } \\
\text { in wind tunnel) }\end{array}$ \\
\hline- & $\begin{array}{l}\text { Linear (friction velocity } \\
\text { in flux chamber) }\end{array}$ \\
\hline
\end{tabular}

Figure 7. Comparison between friction velocity in the flux chamber and in the wind tunnel for various wind speed. 
Table II. Flux chamber: determination of precision and accuracy.

\begin{tabular}{|c|c|c|c|c|c|}
\hline \multicolumn{2}{|c|}{ Operational conditions } & \multirow[b]{2}{*}{$\begin{array}{c}\text { Number of } \\
\text { duplicate } \\
\text { measurements }\end{array}$} & \multirow[b]{2}{*}{$\begin{array}{c}\text { Averaged } \\
\text { emission rates } \\
\left(\mathrm{mg} \cdot \mathrm{m}^{-2} \cdot \mathrm{min}^{-1}\right)\end{array}$} & \multirow[b]{2}{*}{ RDS (\%) } & \multirow[b]{2}{*}{$\begin{array}{c}\text { Averaged bias } \\
(\%)\end{array}$} \\
\hline $\begin{array}{l}\text { Concentration } \\
\text { in water } \\
\left(m g \cdot L^{-1}\right)\end{array}$ & $\begin{array}{c}\text { Wind speed } \\
\left(m \cdot s^{-1}\right)\end{array}$ & & & & \\
\hline 1000 & 5 & 1 & 660 & & 4.1 \\
\hline 100 & 5 & 3 & 97 & 9.8 & -7.2 \\
\hline 1000 & 1 & 1 & 114 & & 2.7 \\
\hline 100 & 1 & 1 & 31 & & 106.7 \\
\hline 550 & 3 & 3 & 161 & 8.6 & -9.0 \\
\hline
\end{tabular}

Table III. Comparison of emission rates in wind tunnel with and without flux chamber present.

\begin{tabular}{|c|c|c|c|c|}
\hline \multirow[b]{2}{*}{$\begin{array}{r}\text { Concentration in } \\
\left(m g \cdot L^{-1}\right)\end{array}$} & Operational conditions & \multicolumn{2}{|c|}{ Emissions rates in wind tunnel } & \multirow[b]{2}{*}{ bias (\%) } \\
\hline & $\begin{array}{l}\text { Wind speed } \\
\quad\left(m \cdot s^{-1}\right)\end{array}$ & $\begin{array}{l}\text { Without flux chamber } \\
\qquad\left(m g \cdot m^{-2} \cdot m^{-1}\right)\end{array}$ & $\begin{array}{l}\text { With flux chamber } \\
\quad\left(m g \cdot m^{-2} \cdot m^{-1}\right)\end{array}$ & \\
\hline 1000 & 5 & 634 & 745 & -17.5 \\
\hline 100 & 5 & 105 & 171 & -62.9 \\
\hline 1000 & 1 & 111 & 154 & -38.7 \\
\hline 100 & 1 & 15 & 26 & -73.3 \\
\hline 100 & 5 & 105 & 119 & -13.3 \\
\hline 100 & 5 & 105 & 157 & -49.5 \\
\hline 550 & 3 & 167 & 301 & -80.2 \\
\hline 550 & 3 & 192 & 550 & -186.5 \\
\hline 550 & 3 & 173 & 478 & -176.3 \\
\hline
\end{tabular}

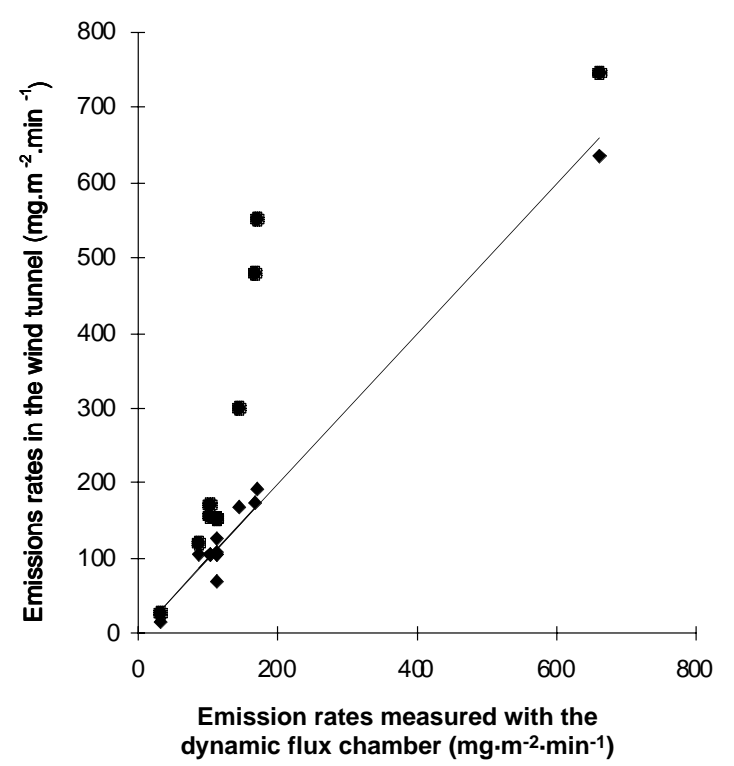

To determine if flux chamber present affects measurement accuracy in the wind tunnel, a comparison between emission rates with and without flux chamber was made. Emission rates, measured in zone $\mathrm{C}$, with flux chamber present cor-
- Emissions rates in wind tunnel without flux chamber

- Emission rates in wind tunnel with flux chamber

$y=x$

Figure 8. Comparison between emission rates in the flux chamber and in the wind tunnel.

responds to the emission from the uncovered surface. The results are reported in table III. A consistent and negative bias is found. 
Figure 8 allows to visually underline both the method accuracy and the existence of a bias. This bias is explained by the dimensions of the flux chamber compared with those of the wind tunnel. The chamber covers $20.8 \%$ of the liquid surface and occupies $5 \%$ of the channel section in the wind tunnel. For similar ratio, some authors [6] have already found an influence due to the flux chamber present. In real environment, the flux chamber would be expected to exert a much smaller impact on the total emission.

Flux chamber has no influence on the precision of emission measurement in the wind tunnel. RSD without flux chamber is $25 \%$ (determined from 5 duplicate measurements with wind speed controlled at $1 \mathrm{~m}^{-\mathrm{s}^{-1}}$ and diethyl sulphide concentration in water fixed at $1000 \mathrm{mg} . \mathrm{L}^{-1}$ ). Average RSD with flux chamber with the same conditions is $23.5 \%$.

\section{Conclusions}

A wind tunnel has been developed as a tool to measure odour emission from areal sources and to test a sampling method. The study of diethyl sulphide concentrations above the liquid surface have shown edge and fetch influence as well as the presence of concentration gradients.

The results corresponding to the study of the dynamic chamber method indicate that liquid surface emission measurements can be made with good precision and accuracy (RSD and averaged bias are less than $10 \%$ ). Operating parameters have not effect on the precision and the accuracy of the method when emission rates are up to $50 \mathrm{mg} \cdot \mathrm{m}^{-2} \cdot \mathrm{min}^{-1}$. Flux chamber present provides a consistent negative bias on uncovered surface emission rates compared with total surface emission without the flux chamber. It is supposed that it may be insignificant on a larger open surface.

Several remarks can be made about the use of chamber method and future works that are needed: firstly, the dynamic flux chamber constructed is a reliable sampling system for measuring emission rates from liquid surfaces. So, the method can be used for generating data for emission inventories until precision and accuracy in the field is determined. Moreover, flux chamber utilisation allows assessing the relative potential emission from different sources. Nevertheless, precision and accuracy on the odour determination using the flux chamber constructed must be studied.
At last, further investigation of using the flux chamber for other types of sources (such as landfills, contaminated soils) are warranted.

\section{References}

1. Frechen, F.B.; Koster, W. Water Sci. Technol. 1998, 38, 6169.

2. Hobbs, P.J.; Misselbrook, T.H.; Pain, B.F. J. Agr. Eng. Res. 1995, 60, 137-144.

3. Hobbs, P.J.; Misselbrook, T.H.; Pain, B.F. J. Sci. Food Agr. 1997, 73, 437-445.

4. Cumby, T.R.; Moses, B.; Nigro, I. Gases from livestock slurries: emission kinetics, $7^{\text {th }}$ Int. Conf. Agr. Food Proc. Wastes, Chicago (USA), 18 June 1995.

5. Eklund, B.M.; Balfour, W.D.; Schmidt, C.E. Environ. Progr. 1985, 4, 199-202.

6. Gholson, A.R.; Albritton, J.R.; Jayanty, R.K.M. Environ. Sci. Technol. 1991, 25, 519-524.

7. Reinhart, D.R.; Cooper, D.C. J. Air Waste Manage. Assoc. 1992, 42, 1067-1070.

8. Sadek, S.E.; Smith, J.D.; Watkin, A.T.; Gebel, R. Environ. Progr. 1996, 15, 82-92.

9. Boholt, K. Evaluation of field methods using flux hoods for measuring odour and VOC from open area sources without outward flow, $4^{\text {th }}$ Int. Conf. on Characterization and control of emissions of odors and VOCs, Montréal (Québec), 20-22 October 1997.

10. Lockyer, D.R. J. Sci. Food Agr. 1984, 35, 837-848.

11. Jiang, K.; Bliss, P.J.; Schulz, T.J. J. Air Waste Manage.Assoc. 1995, 45, 853-859.

12. Bliss, P.; Jiang, J.K.; Schulz, T. J. Air Waste Manage. Assoc. 1995, 45, 989-994.

13. Hwang, S.T. Environ. Progr. 1985, 4, 141-144.

14. Jiang, K.; Kaye, R. Water Sci. Technol. 1996, 34, 583-589.

15. Carney, P.G.; Dodd, V.A. J. Agr. Eng. Res. 1989, 44, 67-76.

16. Liu, Q.; Bundy, D.S.; Hoff, S.J. T. ASAE 1995, 38, 1881-1886.

17. Hobbs, P.J.; Misselbrook, T.H.; Pain, B.F. J. Sci. Food Agr. 1998, 77, 341-348.

18. Keddie, A.W.C. Water Pollut. Control 1982, 266-279.

19. Li, J.; Bundy, D.S.; Hoff, S.J., Liu, Q. ASAE 1994, paper $\mathrm{n}^{\circ}$ 94-4054.

20. Devos, M. Standardized Human Olfactory Thresholds; New York: Oxford University Press, 1990, 165 pages.

21. Lunney, P.H.; Springer, C.; Thibodeaux, L.-J. Environ. Progr. 1985, 4, 203-211.

22. Cohen, Y.; Cocchio, W.; Mackay, D. Environ. Sci. Technol. 1978, 12, 553-558. 